\title{
Physical and Mechanical Characteristics of Shallow Expansive Soil due to Freeze-Thaw Effect with Water Supplement
}

\author{
Yanlong Li $\mathbb{D}^{1,2}$ Zili Wang, ${ }^{1}$ and Yang Luo ${ }^{3}$ \\ ${ }^{1}$ Center for Levee Safety and Disease Prevention Engineering and Technology Research, Ministry of Water Resources, Zhengzhou, \\ Henan 450003, China \\ ${ }^{2}$ School of Civil Engineering, Xuchang University, Xuchang, Henan 461000, China \\ ${ }^{3}$ Shaanxi Key Laboratory of Geotechnical and Underground Space Engineering, Xi'an, Shaanxi 710055, China \\ Correspondence should be addressed to Yanlong Li; liyanlong1229@163.com
}

Received 16 December 2020; Revised 19 February 2021; Accepted 25 February 2021; Published 9 March 2021

Academic Editor: Junping Ren

Copyright (C) 2021 Yanlong Li et al. This is an open access article distributed under the Creative Commons Attribution License, which permits unrestricted use, distribution, and reproduction in any medium, provided the original work is properly cited.

\begin{abstract}
Shear strength of shallow expansive soil varies along with the depth under the freeze-thaw effect. This work investigates shear strength characteristics of shallow expansive soil by simulating the actual freeze boundary conditions of seasonal frozen areas with water supplement. An integrated approach incorporating the freeze-thaw test and direct shear test was adopted. Firstly, unidirectional freezing tests for expansive soil columns under three different freezing temperature gradients were carried out. Secondly, direct shear tests under low vertical stress were performed on the standard samples, which were prepared by using cutting rings cut the thawed expansive soil columns into nine segments along with the depth. Temperature, water content, and dry density at different depths were also investigated after the freeze-thaw process. The test results showed that, after the freeze-thaw process, the shear strength of expansive soil columns showed significant differences along with the depth and highly correlated with water content, specifically the higher water content and the lower shear strength. The minimum shear strength in the expansive soil columns occurred at the soil layer below the frozen and unfrozen zones interface. The expansive soil column's shear strength changed most under the moderate freezing temperature gradient corresponding to the most considerable shear strength reduction. Moreover, the significant decrease in cohesion was the main reason for the shear strength reduction of expansive soil after the freeze-thaw process. These results indicate significant depth variability in shear strength of expansive soil under the freeze-thaw effect.
\end{abstract}

\section{Introduction}

Expansive soil is a highly plastic soil with many hydrophilic clay minerals like montmorillonite and illite. Expansive soil exhibits significant swell-shrink potential and is more prominent shear strength degradation upon climate variations, such as freeze-thaw effect [1-3]. Large areas of expansive soils have been discovered in seasonal frozen regions accompanying the engineering construction. For example, nearly, $380 \mathrm{~km}$ expansive soil open channel in the middle route of South-to-North Water Transfer Project (SNWTP) and more than $260 \mathrm{~km}$ of expansive soil cutting slope in the Jilin-Tumen-Hunchun high-speed railway in China were both located in seasonal frozen regions [4-6]. In these hydraulic engineering and traffic engineering projects, slope instability of expansive soil frequently occurs after the freeze-thaw process. For slope stability analysis, expansive soil's shear strength under the freeze-thaw effect is the necessary mechanical parameter.

When the atmosphere temperature drops below the freezing point under field conditions, the shallow soil will be frozen unidirectional from top to bottom. A typical soil profile for shallow soil in the freezing process includes three parts: the frozen zone, the frozen fringe, and the unfrozen zone [7]. During the freezing process, soil pore water migrates from the unfrozen area to the frozen area under cryogenic suction action [8]. When the atmospheric temperature increases, the upper soil layers begin to thaw first. However, it is difficult for the melted water to infiltrate into the lower layer due to the compacted soil's low permeability. 
Thus, a layer with high water content formed along the plane of the most massive ice lens in the thawed soil, which allows the formation of slurry layers and a consequential weak plane in the soil [9]. Usually, this weak soil layer is the main sliding surface of a soil slope landslide $[10,11]$. It is reasonable to believe that the reduction of shear strength varies with depth after the freeze-thaw process. However, there is a minimal understanding of shear strength characteristics of shallow expansive soil after freeze-thaw.

Laboratory experiments offer a possibility to explore the shear strength variation characteristics of soil under the freeze-thaw effect [12-19]. It needs to be emphasized that the soil samples' freezing and thawing boundary conditions in the laboratory experiments should be consistent with the actual situation on-site. There are two situations for underground water: a high water table and a low water table. If the underground water table is relatively low, it is difficult for water to enter the upper soil. If the groundwater is relatively shallow, water may be induced to migrate upwards and accumulate under cryogenic suction action [20]. An open system and a closed system can be used to simulate high and low underground water tables [21]. Li and Wang [22] have reported shearing strength degradation characteristics of expansive soil due to a closed system's freeze-thaw effect. However, an open system considering external water supplement is a lack of research.

This work aims to investigate the shear strength characteristics of shallow expansive soil along with the depth due to the freeze-thaw effect by simulating the actual freezing boundary conditions in an open system. An integrated approach was to incorporate unidirectional freezing tests, and direct shear tests were adopted. This work is expected to contribute to a clearer understanding of the shallow expansive soil's shear strength characteristics under the freezethaw effect considering water supplement.

\section{Materials and Methods}

2.1. Material Properties. The expansive soil sample was collected from a depth of $1.0 \mathrm{~m}$ on a construction site in Nanyang, Henan province, China. The mineral composition of the expansive soil sample was determined by an X-ray diffractometer (Table 1). The total proportion of expansive clay minerals (montmorillonite and illite) is 58.6\%. The expansive soil sample's physical properties were tested according to the Standard for Soil Test Method (GB/T 501232019) (Table 2). The specific gravity of the expansive soil was 2.73 , which was typical clay. Liquid limit $\left(w_{\mathrm{L}}=69.1 \%\right)$ and plastic limit $\left(w_{\mathrm{p}}=21.3 \%\right)$ indicated the expansive soil sample possessing high water adsorption capacity: the plasticity index $\left(I_{\mathrm{P}}\right)$ was calculated to be $47.8 \%$. Furthermore, the expansive soil sample can be classified as $\mathrm{CH}$ (high plasticity clay). According to the Technical Code for Building in Expansive Soil Regions, the free swelling ratio of 103\% shows that the expansive soil sample has strong expansion potential (GB/T 50112-2013). The maximum dry density was $1.68 \mathrm{~g} /$ $\mathrm{cm}^{3}$ at an optimum water content of $23 \%$. The freezing point of $-1.64^{\circ} \mathrm{C}$ was obtained from the expansive soil samples at the state of $18 \%$ water content and $1.55 \mathrm{~g} / \mathrm{cm}^{3}$ dry density.
TABLE 1: Mineral composition of the expansive soil sample.

\begin{tabular}{lc}
\hline Mineral composition & Content (\%) \\
\hline Montmorillonite & 48.8 \\
Illite & 9.8 \\
Chlorite & 3.4 \\
Kaolinite & 1.2 \\
Quartz & 32.9 \\
Feldspar & 2.8 \\
Dolomite & 1.1 \\
\hline
\end{tabular}

TABLe 2: Physical properties of expansive soil samples.

\begin{tabular}{lc}
\hline Physical index & Value \\
\hline Specific gravity, $G_{\mathrm{s}}$ & 2.73 \\
Liquid limit, $w_{\mathrm{L}}(\%)$ & 69.1 \\
Plastic limit, $w_{\mathrm{p}}(\%)$ & 21.3 \\
Plasticity index, $I_{\mathrm{P}}(\%)$ & 47.8 \\
Free swelling ratio $(\%)$ & 103 \\
Optimum water content $(\%)$ & 23.0 \\
Maximum dry density $\left(\mathrm{g} / \mathrm{cm}^{3}\right)$ & 1.68 \\
Freezing point $\left({ }^{\circ} \mathrm{C}\right)$ & -1.64 \\
\hline
\end{tabular}

2.2. Experiment Equipment. The freeze-thaw device consists of the soil column, temperature control parts, and data measurement and acquisition parts (Figure 1). Soil columns were prepared in a plexiglass tube (height of $36 \mathrm{~cm}$ and diameter of $10 \mathrm{~cm}$ ), which was wrapped by an insulation material to isolate the expansive soil column from the test's external temperature disturbance. A water valve was set at the bottom of the soil columns to control the external water supplement.

Temperature control parts contain two sets of cold baths and a temperature control chamber. The two sets of cold baths can separately control the heat exchangers' temperatures, installed on the top and bottom of the soil columns. A particular freeze environment with different temperature gradients was achieved during the test by applying different temperature combinations on the two heat exchangers. The temperature control chamber with an internal dimension of $80 \mathrm{~cm} \times 60 \mathrm{~cm} \times 60 \mathrm{~cm}$ (height $\times$ width $\times$ depth) was used to control the temperature environment around the soil column. The two heat exchangers' temperature and the temperature control chamber can be controlled with a range from -60 to $40^{\circ} \mathrm{C}$ with an accuracy of $\pm 0.2^{\circ} \mathrm{C}$.

Data measurement and acquisition parts contain nine thermocouples, one displacement transducer, and one data logger. Nine thermocouples (accuracy of $\pm 0.1^{\circ} \mathrm{C}$ ) were horizontally installed with an equal interval of $4 \mathrm{~cm}$ at a depth of $2,6,10,14,18,22,26,30$, and $34 \mathrm{~cm}$ in the expansive soil columns to monitor the internal temperature dynamic change during freeze-thaw process. The displacement transducer (accuracy of $\pm 0.01 \mathrm{~mm}$ ) was placed on the top heat exchanger to monitor the soil columns' vertical deformation during the test.

The direct shear apparatus is controlled by a servo control system, which can automatically record the horizontal displacement and shear stress. The main technical parameters of the direct shear apparatus are as follows: 


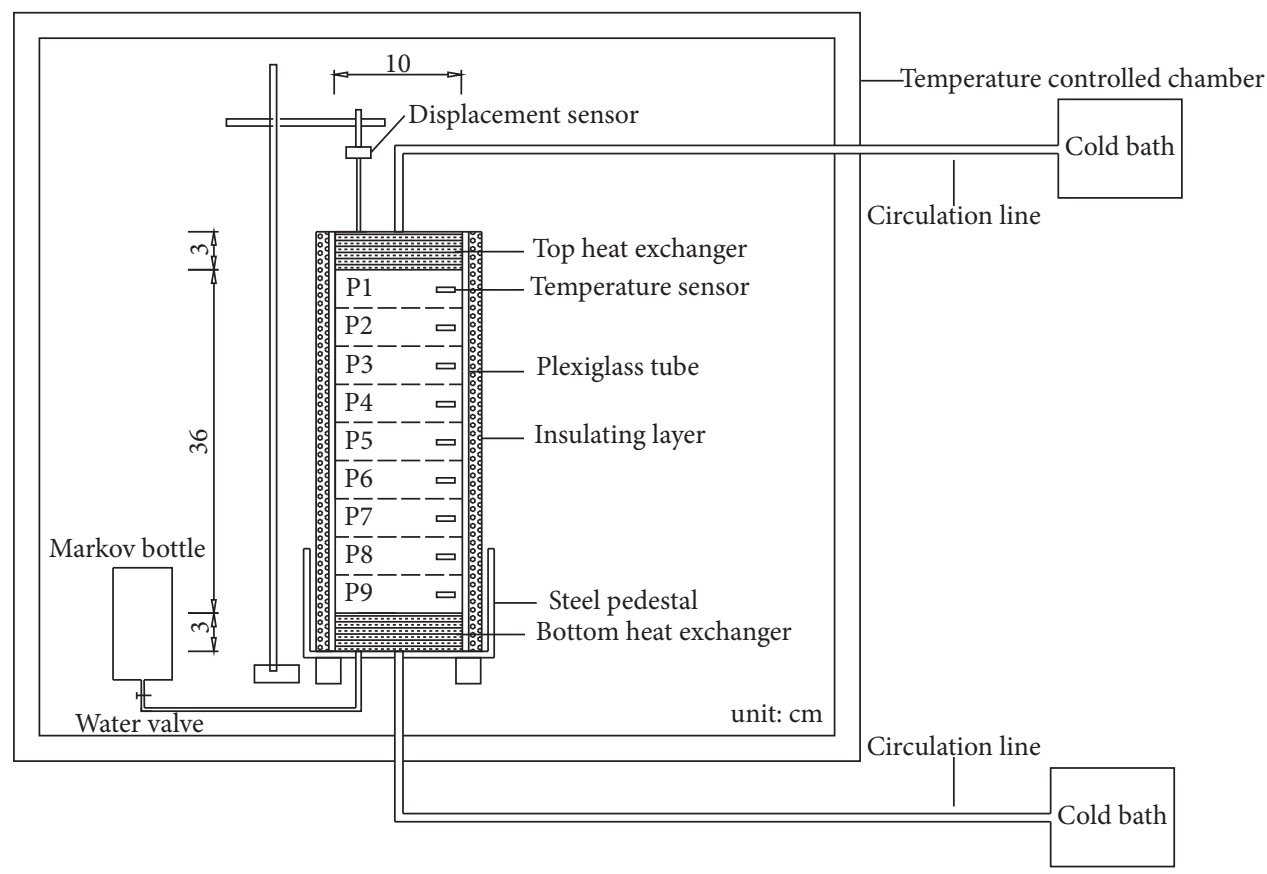

Figure 1: Schematic diagram of the unidirectional freezing test.

$300 \mathrm{kN}$ maximum shear stress with a precision of $\pm 5 \mathrm{~N}$, five strain rates $(0.02,0.04,0.08,1.00$, and $2.00 \mathrm{~mm} / \mathrm{min}), 50 \mathrm{~mm}$ maximum horizontal displacement with $\pm 0.01 \mathrm{~mm}$ precision, and $20 \mathrm{~mm}$ vertical displacement transducer with $0.01 \mathrm{~mm}$ precision.

2.3. Experiment Process. The experiment process consists of three procedures: expansive soil columns preparation, freeze-thaw tests, and direct shear tests. Predetermined amounts of water and air-dried soil samples after screening from a $2.0 \mathrm{~mm}$ sieve were mixed and allowed to equilibrate for $24 \mathrm{~h}$ in sealed bags to achieve an initial water content of $18 \%$ and then dynamically compacted in six layers in the plexiglass tube. The dry densities of all soil columns were controlled to be $1.6 \mathrm{~g} / \mathrm{cm}^{3}$. Vaseline was smeared on the plexiglass tube's internal face before soil compaction to reduce boundary friction.

Three different freezing schemes (F1, F2, and F3) were adopted in unidirectional freezing tests (Table 3 ). Moreover, the different freezing schemes had different freezing temperature gradients by setting different temperature combinations to the two heat exchangers. The top heat exchangers' temperatures were set as $-5,-10$, and $-15^{\circ} \mathrm{C}$, corresponding to freezing schemes F1, F2, and F3, respectively. Furthermore, the bottom heat exchangers were always controlled to be $+1^{\circ} \mathrm{C}$ during the freezing process. Therefore, the three freezing temperature gradients were $0.17,0.31$, and $0.44^{\circ} \mathrm{C} \cdot \mathrm{cm}^{-1}$, respectively. All the expansive soil columns were precooled at $+1^{\circ} \mathrm{C}$ in the temperature control chamber for $24 \mathrm{~h}$ before freezing tests, and then exposed at different freezing schemes until the Markov bottle's water level is no longer falling, which means water migration is adequate [23]. After the freezing process, the expansive soil columns were thawed at room temperature $\left(+15^{\circ} \mathrm{C}\right)$ until reaching a
TABLE 3: Freezing temperature gradients and corresponding temperature combinations.

\begin{tabular}{lccc}
\hline & $\begin{array}{c}\text { The heat } \\
\text { exchanger } \\
\text { temperature } \\
\left({ }^{\circ} \mathrm{C}\right)\end{array}$ & Temperature gradient $\left({ }^{\circ} \mathrm{C} \cdot \mathrm{cm}^{-1}\right)$ \\
& Top & Bottom & \\
\hline F1 & -5 & 1 & 0.17 \\
F2 & -10 & 1 & 0.31 \\
F3 & -15 & 1 & 0.44 \\
\hline
\end{tabular}

stable thermal state. The displacement transducer was placed on the top heat exchanger to monitor the soil columns' vertical deformation all through the freezing-thawing test. The water valve was opened during the whole freeze-thaw process to allow external water supplement [24].

After thawing, cut the thawed expansive soil columns into nine segments $(4 \mathrm{~cm}$ thick) along with the depth. Cutting rings are used to prepare the standard direct shear sample $(20 \mathrm{~mm}$ height and $61.8 \mathrm{~mm}$ diameter $)$ in each segment. After standard direct shear sample preparation, each segment's water content was determined by the drying method on the remaining expansive soils. Each segment's dry density was calculated using phase relationships based on the measured water content and the measured cutting sample weight.

A quick direct shear test with a constant strain rate of $0.08 \mathrm{~mm} / \mathrm{min}$ was adopted during the test to avoid soil structure change in the freeze-thaw process. A series of low normal stresses $(25,50,75$, and $100 \mathrm{kPa})$ were utilized in the direct shear test to reflect the actual stress state of shallow expansive soil [25]. The direct shear test terminated as a shear displacement was $4.0 \mathrm{~mm}$ if a peak reading was shown 
in the dynamometer; otherwise, it is stopped at the shear displacement of $6.0 \mathrm{~mm}$. The relationship curves between shear stress and shear displacement were plotted when the direct shear tests were finished. The peak value of shear stress on the relationship curve between shear stress and shear displacement was appointed as the shear strength of each sample. If there was no peak value, the shear stress corresponding to the shear displacement of $6 \mathrm{~mm}$ was taken as shear strength. The shear strength parameters (cohesion and internal friction angle) were obtained from the strength envelopes obtained based on the stress-strain curves. The direct shear test under the same conditions for identical expansive soil samples without freeze-thaw effect was also carried out for comparison.

2.4. Data Analysis Method. A dimensionless parameter, vertical deformation rate $(\varepsilon)$, was defined to reflect the vertical deformation ratio after freezing or thawing and calculated by

$$
\varepsilon=\frac{z_{p}-z_{0}}{h_{0}} \times 100 \%
$$

where $\varepsilon$ is the vertical deformation ratio, $z_{p}$ is the reading of the displacement sensor after freezing or thawing process, $z_{0}$ is the initial reading of the displacement sensor at the beginning of the testing, and $h_{0}$ is the original height of the soil sample. When $\varepsilon$ it is positive, it refers to volume expansion; if contrary, it represents volume contraction.

The shear strength ratio ( $S$-ratio), cohesion ratio ( $C$-ratio), internal friction angle ratio ( $A$-ratio), water content ratio $(W$ ratio), and dry density ratio ( $D$-ratio), respectively, were calculated by equation (2). The ratio greater than 1.0 indicates the parameter increase, and correspondingly, the ratio less than 1.0 indicates a decrease in the parameter due to freezethaw:

$$
S, C, A, W, D=\frac{\text { data after freeze }- \text { thaw process }}{\text { data of the unfrozen soil }} .
$$

\section{Results}

3.1. Frozen Characteristics of Expansive Soil Columns. During the freezing process, the temperature dynamic characteristics of each expansive soil column were different (Figure 2). After freezing for $24 \mathrm{~h}, 48 \mathrm{~h}$, and $72 \mathrm{~h}$, expansive soil columns' temperature profiles corresponding to schemes F1, F2, and F3 were all linearly distributed along with the depth, which indicates that the thermal states of the soil columns have been reached stable. The expansive soil columns' frozen depths reached $21 \mathrm{~cm}, 26 \mathrm{~cm}$, and $29 \mathrm{~cm}$, corresponding to freezing schemes F1, F2, and F3, respectively. All the expansive soil columns were divided into the frozen zone and unfrozen zone according to the freezing point of $-1.64^{\circ} \mathrm{C}$, considering the thickness of the frozen fringe is very small, usually ranging from $1.5 \mathrm{~mm}$ to $8 \mathrm{~mm}$ $[26,27]$. Each expansive soil column's temperature dynamic characteristics were also varied with freezing schemes (Figure 3). After thawing for $18 \mathrm{~h}, 32 \mathrm{~h}$, and $48 \mathrm{~h}$, expansive soil columns' temperature profiles corresponding to scheme F1, F2, and F3 were all reached stability.

The expansive soil columns' water content profiles exhibited significant differences along with depth after thawing and varied with different freezing schemes (Figure 4). The water content of each soil columns all increased at different depths. The water content increased significantly in the frozen soil area while it increased little in the unfrozen area. The free water was sucked from the Markov bottle to the bottom of the soil columns; then, soil pore water migrated from the unfrozen zone to the frozen zone under the temperature gradients during the freezing process. The expansive soil column's average water content was $21.7 \%$, $23.6 \%$, and $22.3 \%$, corresponding to freezing schemes F1, F2, and F3, respectively. The water content at the frozen and unfrozen zone interface was highest except for the bottom of the soil columns and that was $23.3 \%, 28.2 \%$, and $26.9 \%$, corresponding to freezing schemes F1, F2, and F3, respectively. The amount of water migration was from scheme F2, $\mathrm{F} 1$, and F3 in the descending order.

The expansive soil columns' dry density profiles also exhibited significant differences along with the depth after thawing and varied with different freezing schemes (Figure 5). The dry densities were generally decreased and less than the initial dry density $\left(1.60 \mathrm{~g} / \mathrm{cm}^{3}\right)$ at different depths. The mean dry densities were $1.57 \mathrm{~g} / \mathrm{cm}^{3}, 1.55 \mathrm{~g} / \mathrm{cm}^{3}$, and $1.56 \mathrm{~g} / \mathrm{cm}^{3}$, corresponding to freezing schemes $\mathrm{F} 1, \mathrm{~F} 2$, and F3. The minimum dry densities were $1.52 \mathrm{~g} / \mathrm{cm}^{3}, 1.50 \mathrm{~g} / \mathrm{cm}^{3}$, and $1.51 \mathrm{~g} / \mathrm{cm}^{3}$, corresponding to freezing scheme $\mathrm{F} 1, \mathrm{~F} 2$, and F3, obtained at the interfaces of the frozen and unfrozen zones for each specimen. Changes in dry density mean changes in soil structure, and the decrease in dry density means that the soil structure becomes loose.

The deformation rates of each expansive soil column were positive both in the freezing and thawing processes, and they were also varied with freezing schemes (Figure 6). For schemes F1, F2, and F3, the deformation rates were $4.1 \%$, $5.3 \%$, and $2.8 \%$ after the freezing process and $2.9 \%, 3.6 \%$, and $2.4 \%$ after the thawing process. Expansive soil columns showed a frost heave phenomenon during the freezing process. The expansive soil columns' deformation showed a slight decrease during the thawing process than the freezing process. The expansion deformation that existed after the thawing process indicates the expansive soil columns' structure has been changed.

3.2. Shear Strength Characteristics. Shear strength of the expansive soil columns at different depths, under different freezing schemes, and different normal stress after the freeze-thaw process are listed in Table 4; besides, the expansive soil samples' shear strength without freeze-thaw effect is $32.9 \mathrm{kPa}, 58.3 \mathrm{kPa}, 91.3 \mathrm{kPa}$, and $119.3 \mathrm{kPa}$, corresponding to the normal stress of $25 \mathrm{kPa}, 50 \mathrm{kPa}, 75 \mathrm{kPa}$, and $100 \mathrm{kPa}$, respectively. The shear strength ratio ( $S$-ratio), water content ratio ( $W$-ratio), and dry density ratio ( $D$-ratio) were calculated by equation (2).

The $S$-ratios showed significant differences along with each expansive soil column's depth and were less than 1.0 (Figure 7). The $S$-ratios decreased rapidly at the bottom of 

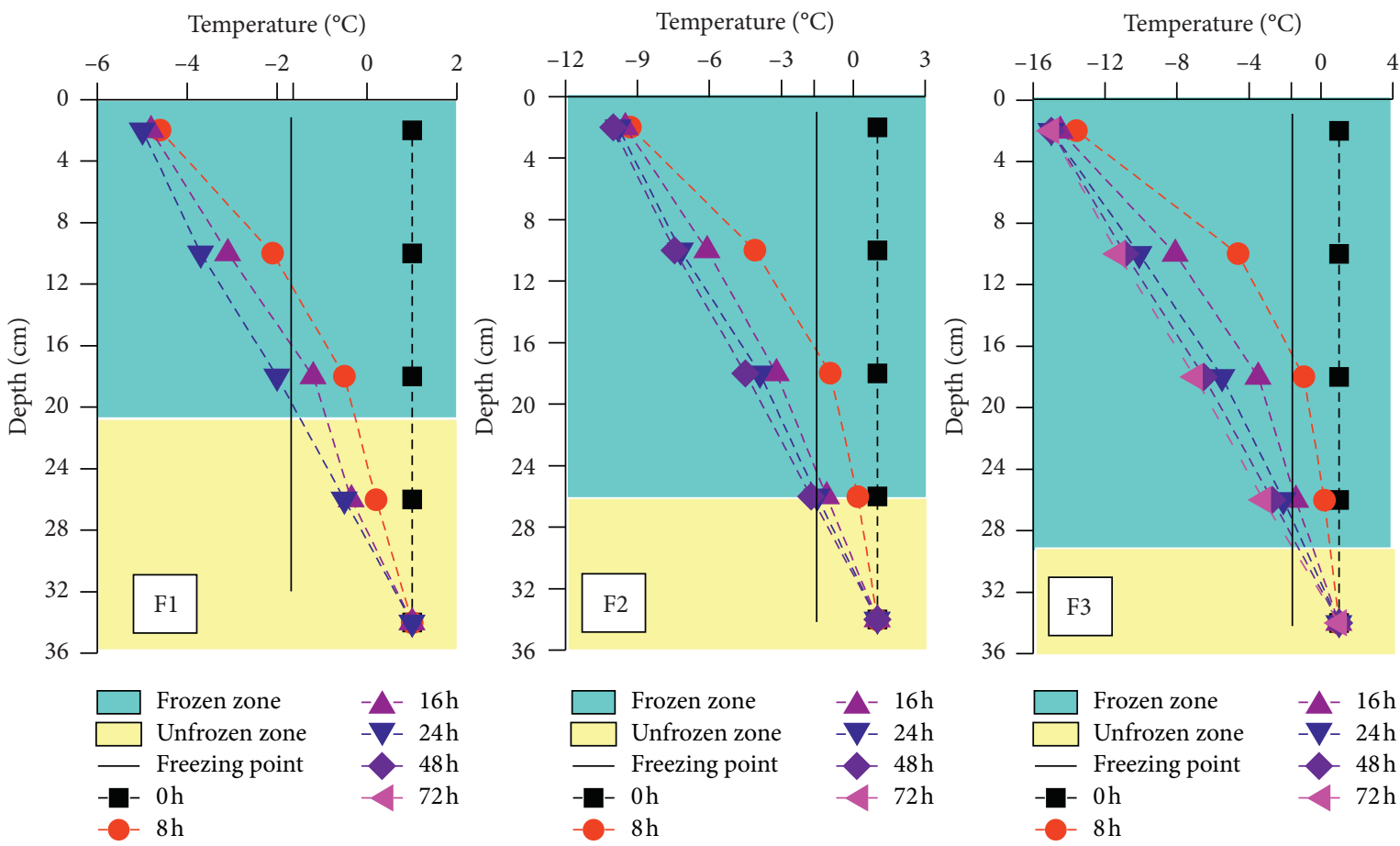

FIgURE 2: Temperature profiles of the expansive soil columns during the freezing process.
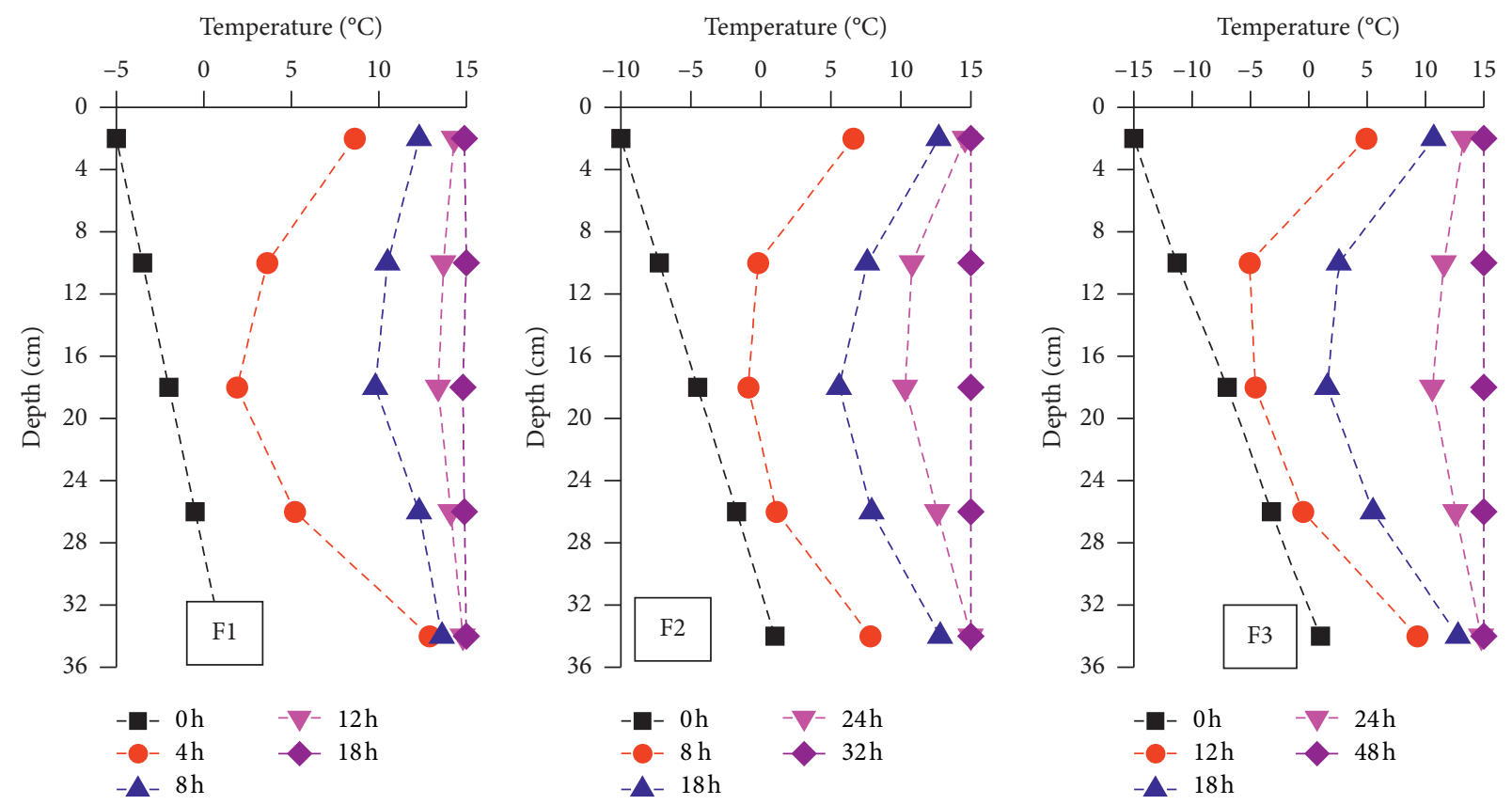

FIgURE 3: Temperature profiles of the expansive soil columns during the thawing process.

the expansive soil column. The minimum $S$-ratios under different freezing schemes were all obtained at the interfaces of the frozen zones and unfrozen zones. Taking the normal stress of $50 \mathrm{kPa}$ as an example, the average $S$-ratios of the expansive soil in the frozen zone was $0.82,0.75$, and 0.77 and those in the unfrozen zone were $0.65,0.64$, and 0.66 , and the minimum $S$-ratios were $0.64,0.63$, and 0.65 corresponding to freezing schemes F1, F2, and F3, respectively. The results indicate that the shear strength reduction in the frozen zone is smaller than that in the unfrozen zone. Another phenomenon was that the average decrease in $S$-ratios of the expansive soil in frozen zones was F2, F1, and F3 in the descending order.

The relationship curves between $S$-ratio (normal press $25 \mathrm{kPa}$ and $100 \mathrm{kPa}$ ) and $W$-ratio and $D$-ratio were plotted in Figures 8 and 9 . There is a high correlation between the $S$ - 


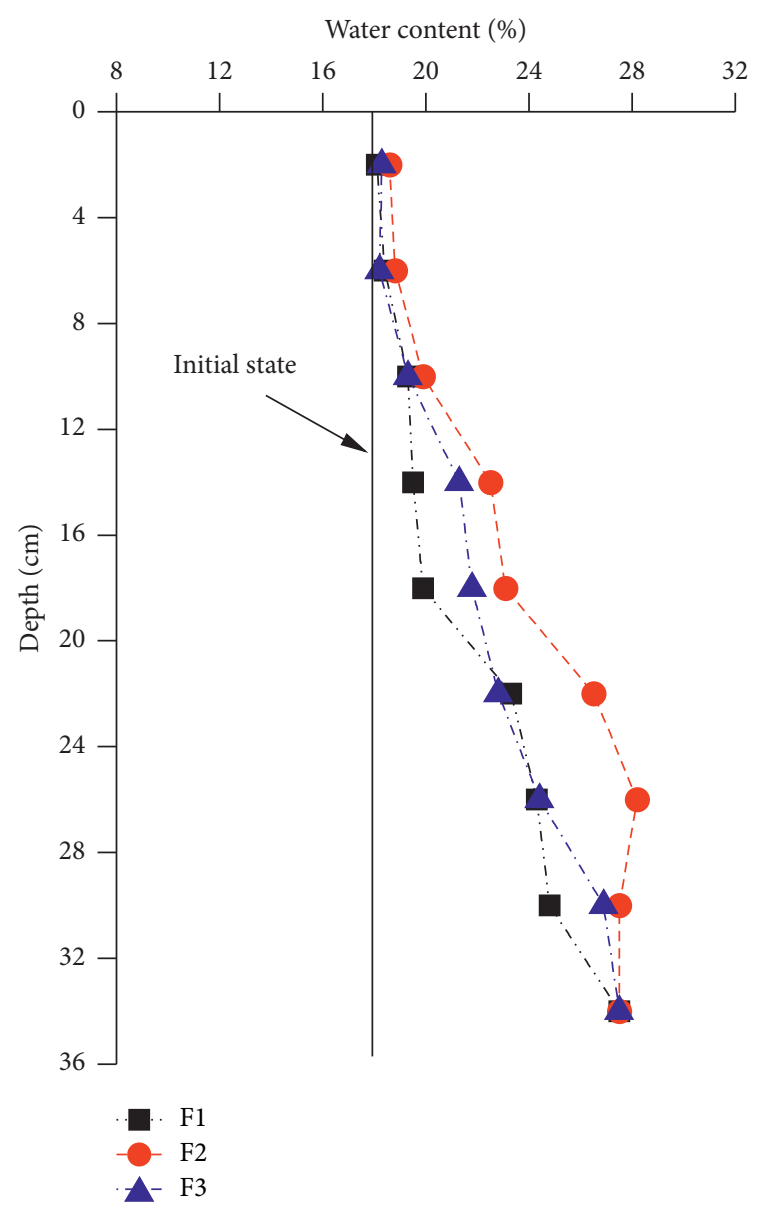

FIGURE 4: Water content profiles of the expansive soil columns after the freeze-thaw process.

ratios and $W$-ratios in the variation law. All the $S$-ratios' reduction in the frozen zone was relatively small, corresponding to the small increase in the W-ratios'. In the unfrozen zone, the $S$-ratios showed a substantial reduction, corresponding to the $W$-ratios' substantial increase. In particular, both the $S$-ratios and $W$-ratios achieved minimum and maximum values at the freeze-thaw interface of the frozen and unfrozen zones, respectively. However, the correlation between the $S$-ratios and $D$-ratios in the frozen zone was low (Figure 9). All the average $D$-ratios in the unfrozen zones was 0.96 , and in the frozen zones, it was 0.98 , corresponding to freezing schemes F1, F2, and F3. Nevertheless, the average $S$-ratios in the frozen zone was $0.82,0.75$, and 0.77 and those in the unfrozen zone were $0.65,0.64$, and 0.66 .

3.3. Shear Strength Parameter Characteristics. The cohesion ratio ( $C$-ratio) and the internal friction angle ( $A$-ratio) at the expansive soil columns' different depths after the freeze-thaw process were calculated by equation (2) and plotted in Figures 10 and 11. Note that the expansive soil samples' cohesion and internal friction angle without freeze-thaw effect was $34.1 \mathrm{kPa}$ and $22.1^{\circ}$, respectively. Both of the $C$-ratios and $A$-ratios were less than 1.0 at the whole

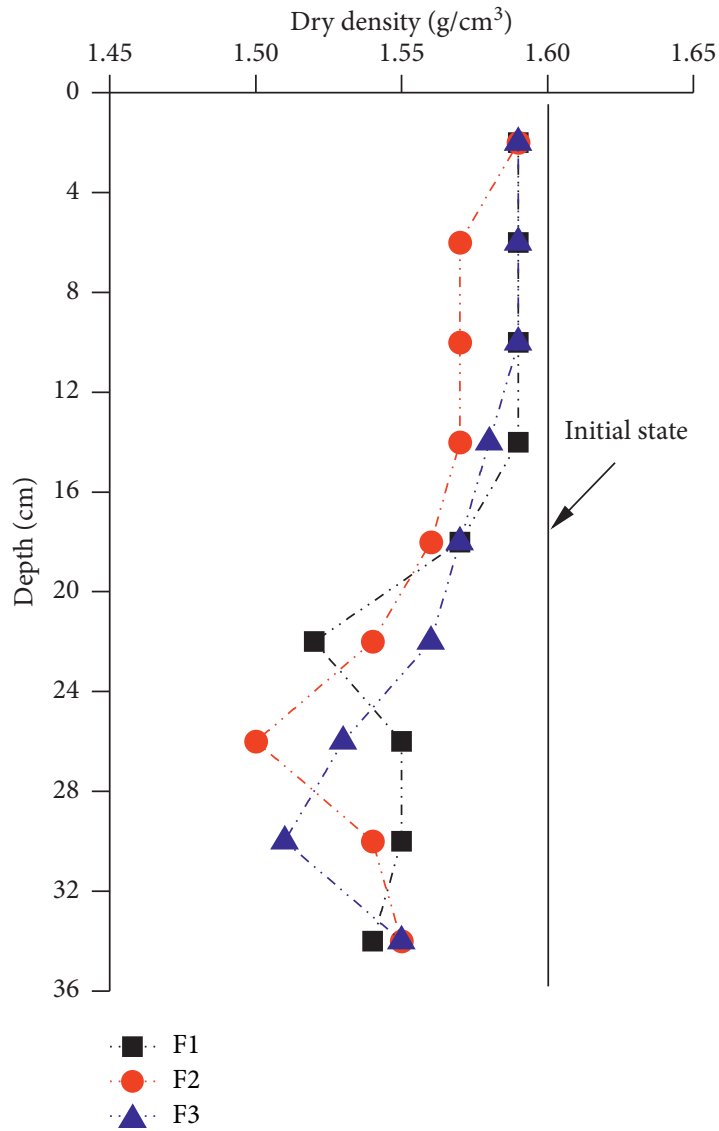

FIGURE 5: Dry density profiles of the expansive soil columns after the freeze-thaw process.

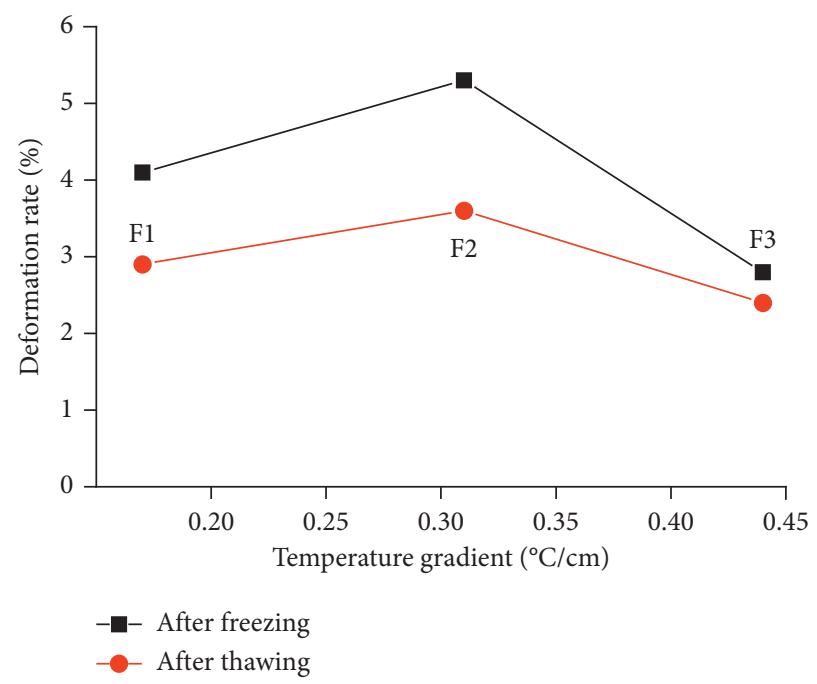

Figure 6: Deformation rates of the expansive soil columns after freezing and thawing processes.

expansive soil columns, but they were varied with freezing schemes. For freezing schemes F1, F2, and F3, the average $C$-ratios were $0.72,0.64$, and 0.69 , while the average $A$ ratios were $0.97,0.96$, and 0.96 , respectively. The reduction 
TABLE 4: Shear strength of expansive soil columns at different depths under different normal stress after the freeze-thaw process.

\begin{tabular}{|c|c|c|c|c|c|c|c|c|c|c|c|c|}
\hline \multirow{3}{*}{ Depth $(\mathrm{cm})$} & \multicolumn{12}{|c|}{ Shear strength $(\mathrm{kPa})$} \\
\hline & \multicolumn{3}{|c|}{$25 \mathrm{kPa}$} & \multicolumn{3}{|c|}{$50 \mathrm{kPa}$} & \multicolumn{3}{|c|}{$75 \mathrm{kPa}$} & \multicolumn{3}{|c|}{$100 \mathrm{kPa}$} \\
\hline & $\mathrm{F} 1$ & $\mathrm{~F} 2$ & F3 & $\mathrm{F} 1$ & $\mathrm{~F} 2$ & F3 & $\mathrm{F} 1$ & $\mathrm{~F} 2$ & F3 & $\mathrm{F} 1$ & $\mathrm{~F} 2$ & F3 \\
\hline 2 & 27.9 & 25.4 & 27.1 & 51.7 & 47.4 & 49.1 & 82.5 & 76.8 & 80.0 & 111.2 & 104.1 & 108.4 \\
\hline 6 & 27.9 & 24.6 & 26.9 & 51.7 & 47.0 & 49.4 & 82.9 & 76.4 & 80.1 & 110.8 & 103.7 & 107.5 \\
\hline 10 & 27.9 & 24.6 & 26.7 & 50.2 & 46.0 & 48.3 & 81.3 & 75.7 & 79.2 & 109.6 & 102.7 & 105.8 \\
\hline 14 & 27.4 & 23.0 & 25.3 & 49.9 & 43.6 & 45.6 & 81.7 & 74.7 & 77.8 & 109.4 & 101.1 & 103.9 \\
\hline 18 & 25.7 & 22.4 & 23.6 & 47.1 & 42.4 & 44.6 & 79.5 & 72.9 & 74.4 & 106.9 & 98.6 & 101.5 \\
\hline 22 & 20.3 & 22.1 & 23.2 & 37.8 & 40.7 & 43.2 & 62.4 & 66.5 & 72.5 & 84.9 & 89.0 & 99.3 \\
\hline 26 & 20.4 & 20.0 & 22.2 & 38.0 & 37.2 & 42.0 & 63.3 & 61.0 & 71.0 & 86.5 & 84.0 & 95.3 \\
\hline 30 & 20.5 & 19.8 & 20.7 & 38.1 & 37.6 & 38.0 & 63.6 & 61.5 & 62.2 & 86.9 & 86.4 & 86.1 \\
\hline 34 & 20.4 & 20.0 & 20.6 & 38.1 & 37.3 & 38.4 & 63.7 & 61.4 & 63.0 & 87.0 & 85.2 & 86.2 \\
\hline
\end{tabular}
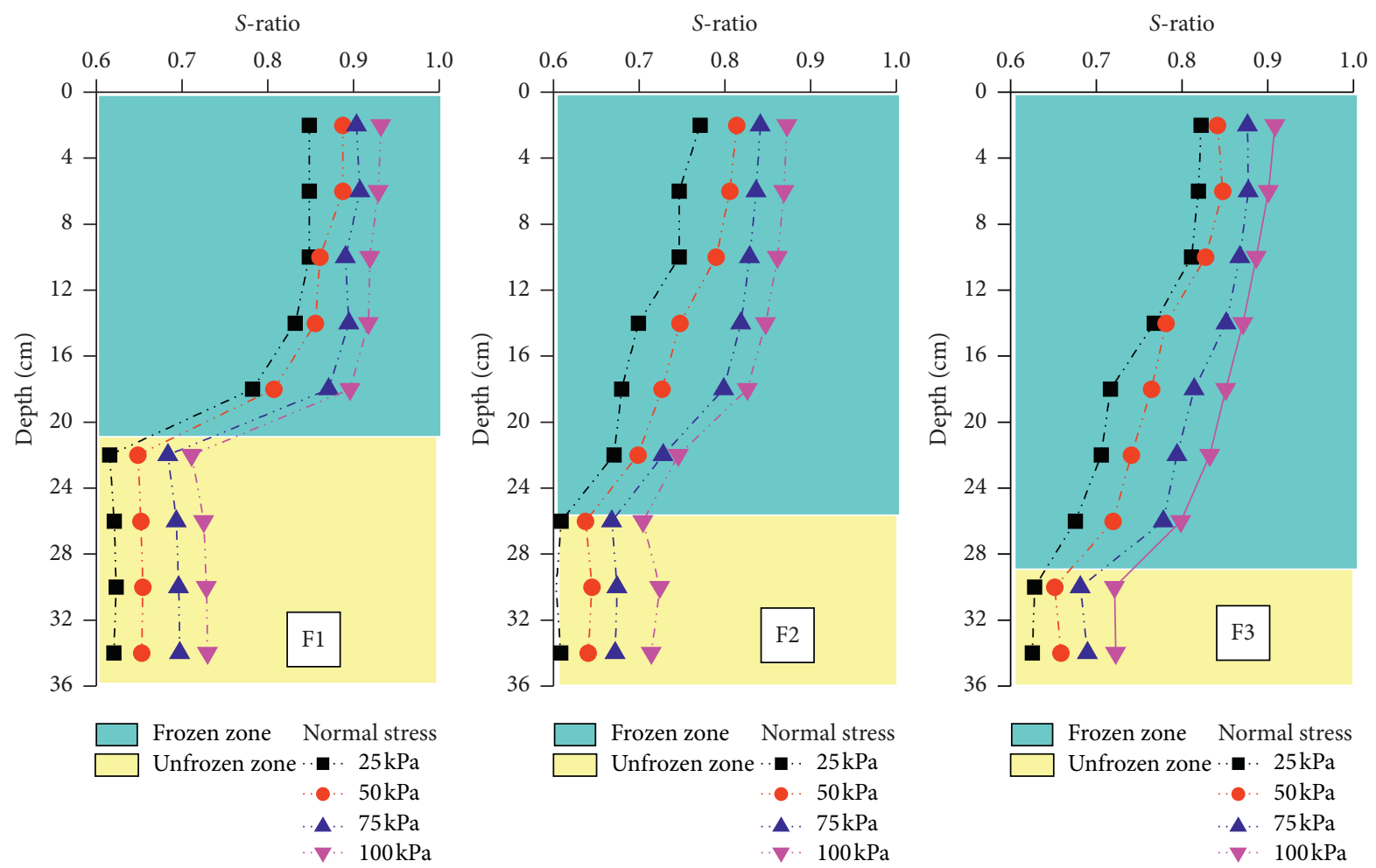

Figure 7: Shear strength ratio ( $S$-ratio) at the expansive soil columns' different depths after the different freeze-thaw process.

in $C$-ratios was much higher than the $A$-ratios. The mean $C$-ratios in the frozen zones were $0.79,0.74$, and 0.66 but those in the unfrozen zone were $0.58,0.54$, and 0.50 , corresponding to freezing schemes F1, F2, and F3. Three obvious inflection points between the frozen and nonfrozen regions in the $C$-ratios curves can be seen in Figure 10. The $A$-ratios changes little in both frozen and unfrozen zones (Figure 11).

\section{Discussion}

4.1. Relationship between Shear Strength and Frozen Characteristics. The minimum shear strength in the expansive soil columns occurred at the soil layer below the frozen and unfrozen zone interface. The reduction of shear strength is attributed to the soil structure damage during the freezing process [28]. The formation of irregular pores and large cracks due to water migration and water phase change in soil particles and pores is the main reason for soil structure damage [29-31]. The more significant the water migration, the more the considerable changes in the soil structure, which induce more significant degradation of soil shear strength. The inhomogeneity of shear strength along depth is consistent with that of water content along with the depth. Changes in soil water potential in response to temperature gradients during the freezing process induce a situation in which soil water migrates from the unfrozen zone to the frozen zone $[32,33]$. Moreover, the necessary condition for water migration is that the water migration rate must be higher than the freezing rate [34]. A higher freezing rate formed by a large temperature gradient can lead to an insufficient moisture migration due to pore water 

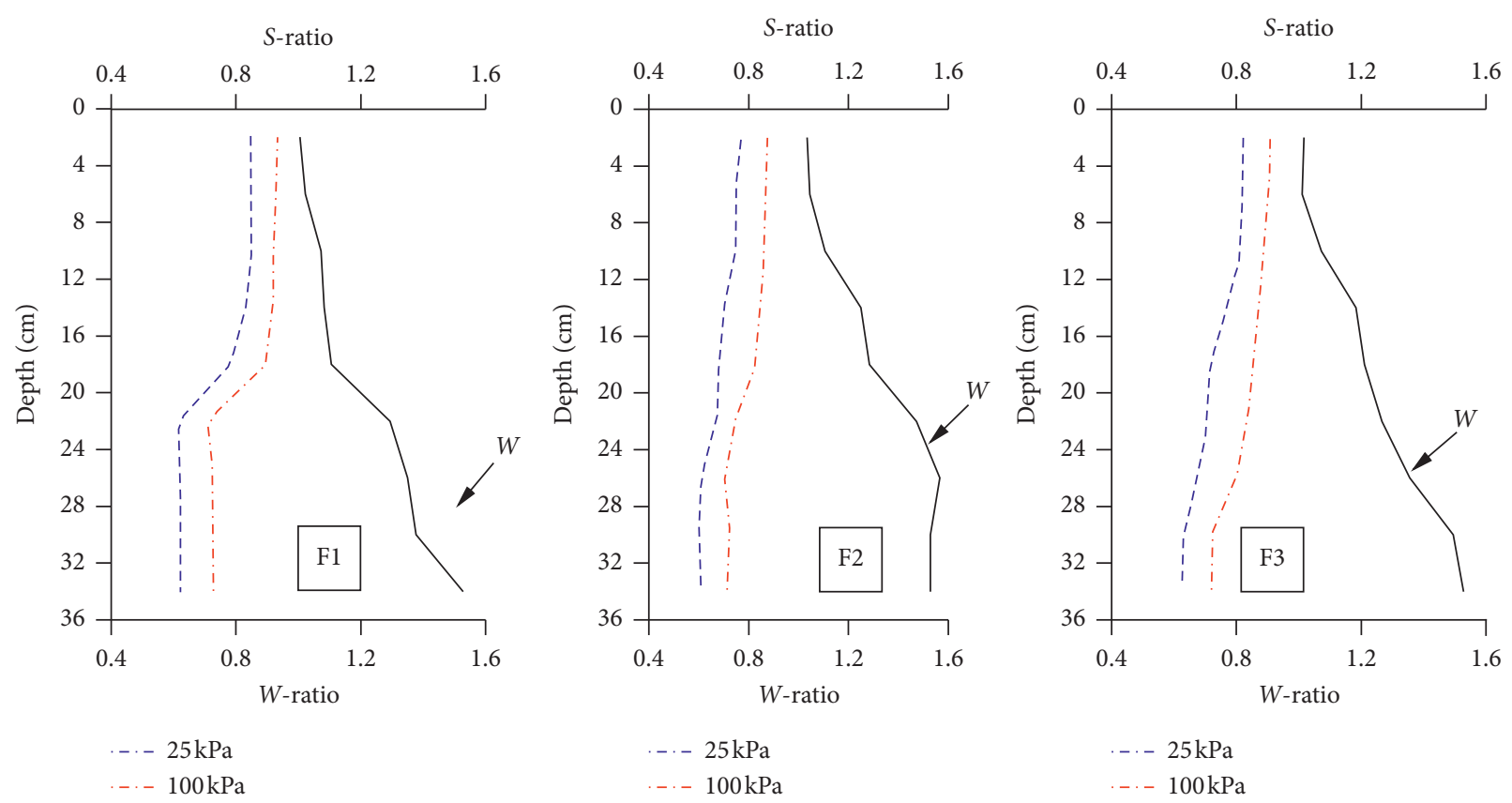

FIgURE 8: Shear strength ratio ( $S$-ratio) versus water content ratio ( $W$-ratio) at the expansive soil columns' different depths after the freezethaw process.
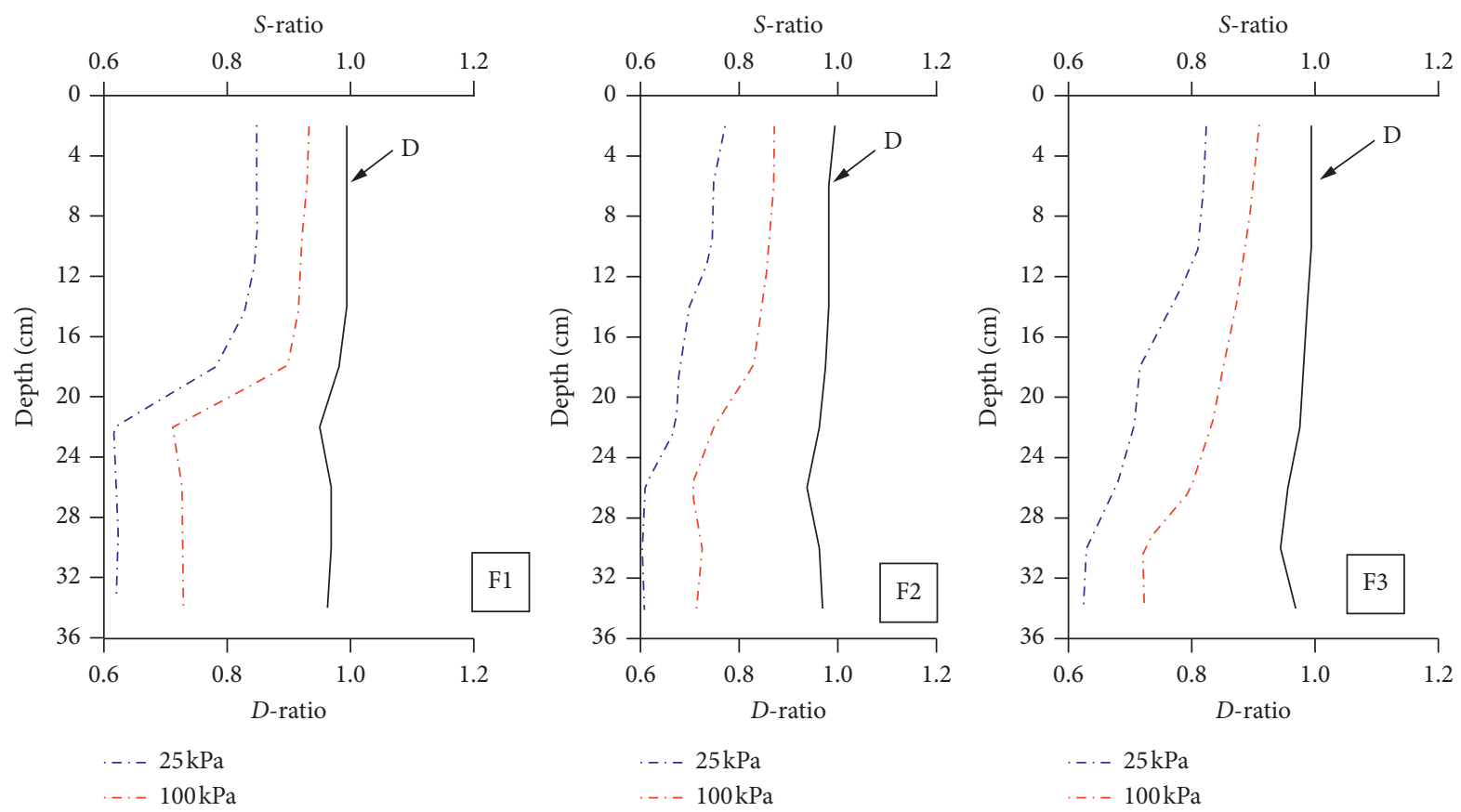

FIGURE 9: Shear strength ratio ( $S$-ratio) versus dry density ratio ( $D$-ratio) at the expansive soil columns' different depths after the freeze-thaw process.

freezing rapidly. On the contrary, the lower freezing rate cannot provide enough driving force for pore water migration. The amount of water migration under moderate freezing temperature gradient (scheme F2) is most considerable than the low and high freezing temperature gradients (Figure 4), and similar observations have also been reported by Talamucci [35]. Thus, the shear strength degradation for freezing scheme F2 was more evident than that of F1 and F3 accordingly.

Moreover, this is similar to the findings reported by Steiner et al. [9], who reported that the most substantial change inshear strength of an illite clay occurred between $-5^{\circ} \mathrm{C}$ and $-10^{\circ} \mathrm{C}$ due to the formation of large ice lenses at such moderate temperature range, and these lenses acted as 


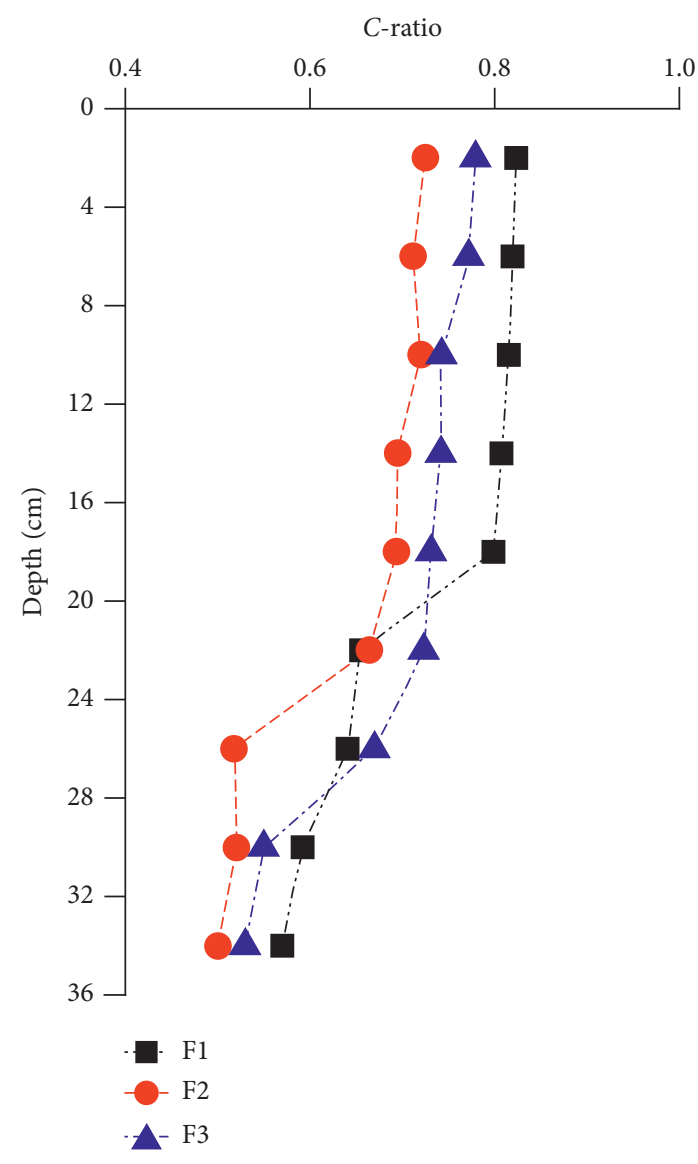

Figure 10: The cohesion ratio ( $C$-ratio) at different depths of the expansive soil columns after the freeze-thaw process.

the primary failure plane in the thawed soil and caused a reduction in shear strength. During the freezing process, a violent water-ice phase transition occurs at the interface of frozen and unfrozen zones (freezing front) in which has the highest ice content. As the upper soil layers beg into thaw, the melted water does not easily infiltrate into the lower layer due to the compacted soil's low permeability. Therefore, the lowest shear strength occurred at the frozen-unfrozen zones interface corresponding to the maximum water content. In an open system, due to water replenishment from the soil columns' bottom, the water content at soil columns' bottom was relatively high, and the bottom soil softens, so the shear strength at the bottom decreases significantly.

In addition to water content, dry density is generally considered another critical factor that has a significant effect on shear strength, and the shear strength increases with the increase of dry density under other fixed conditions [36, 37]. The dry density changes (the average $D$-ratio 0.98 ) were minimal in the frozen zones and unfrozen zones. Therefore, the effect of changes in dry density on shear strength is limited. The expansive soil columns' volume has slightly expanded after thawing, consistent with the dry density's slight decrease. Frost heave and thawing settlement are typical soil deformation characteristics during the freezethaw process $[38,39]$. It is worth noting that the expansive soil columns showed a phenomenon of frost expansion and

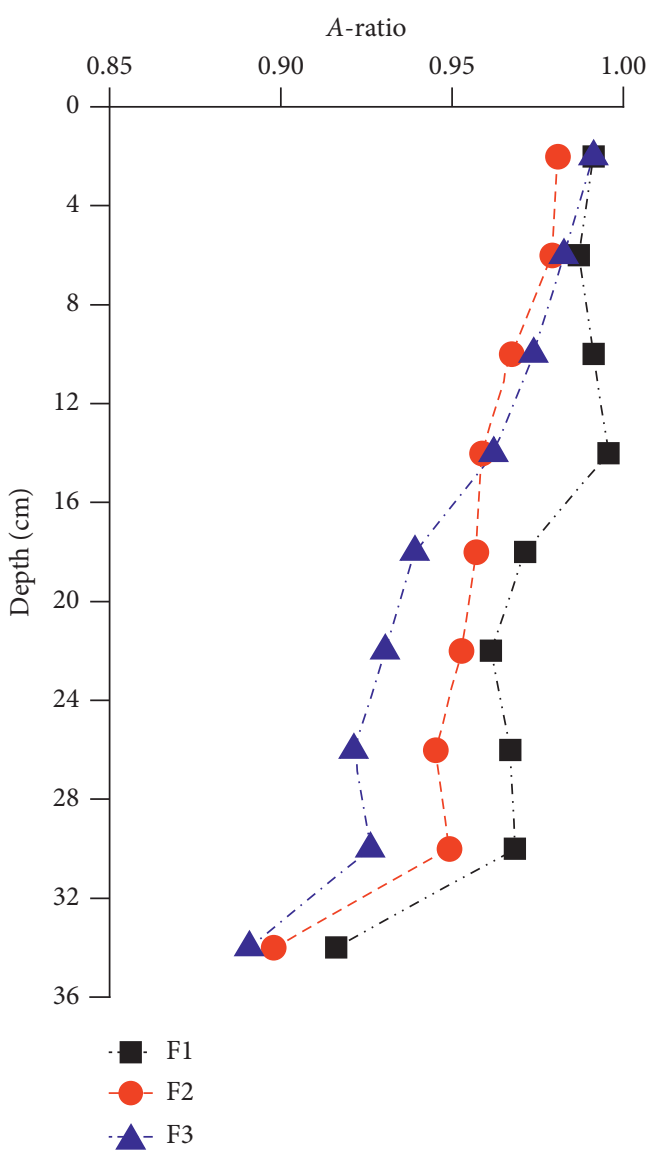

Figure 11: The internal friction angle ( $A$-ratio) at different depths of the expansive soil columns after the freeze-thaw process.

thawing expansion (Figure 6). Different observations have been found in a compacted expansive soil reported by $\mathrm{Lu}$ et al. [17], who found that, for expansive soils with lower water content, the overall deformation decreases upon freezing but increases thawing. Hamilton [40] reported that regardless of whether expansion or contraction during the freezing process, the volumes presented expansion for compacted soil at the end of the thawing process. Viklander [41] reported that the volume typically decreased for initially loose soil and increased for a dense soil after freeze-thaw, and independent of whether the initial soil structure was loose or dense, a constant "residual" void ratio could be obtained after 1-3 cycles. The residual deformation between the freezing and thawing stages indicates that the soil structure has been changed, directly affecting the thawed soil's shear strength.

\subsection{Shear Strength Parameter Characteristics after Freeze-} Thaw. The cohesion of expansive soil that underwent freezethaw effect was significantly reduced, while the internal friction angle was slightly reduced and not noticeable. The decrease of cohesion is mainly induced by weakening of soil cementation, which results from cracks developed by ice lens growth during the freezing process $[42,43]$. The cohesion decreased after freeze-thaw has been recognized by scholars 
$[9,16,19]$. The change of internal friction angle of the soils after freeze-thaw is still controversial. The increased results, decreased results, and consistent results all can be found in the literature $[12,14,15,18]$. There are two opposite effects on the internal friction angle of the soils subjected to freezethaw. On the one hand, the increase of contact points between soil particles induced by the freeze-thaw effect can increase the internal friction angle; on the other hand, the lubrication effect caused by the increase of water content can reduce the internal friction angle [44]. The final results are the interaction of the two opposite effects mentioned above. As for expansive soil, Tang et al. [5] found that the internal friction angle decreased significantly after one freeze-thaw cycle, which is different from our results. The difference between the results may be attributed to the differences in test methods.

Only the initial water content of $18 \%$ was studied in the present work, and it is necessary to study the influence of initial water content and water replenishment on shear strength in future research. Besides, the influence of freezethaw cycles on shallow expansive soil's shear strength also needs further investigation.

\section{Conclusions}

The shear strength characteristics of shallow expansive soil due to the freeze-thaw effect with water supplement were investigated using an integrated approach that incorporated the unidirectional freezing test and direct shear test. We found that shallow expansive soil's shear strength after the freeze-thaw effect showed significant differences with depth and was highly correlated with water content. Furthermore, the most considerable reduction of the shear strength of expansive soil after freeze-thaw was under the moderate freezing temperature gradient. Moreover, the significant decrease in cohesion makes a prominent contribution to reducing the shear strength after freeze-thaw.

\section{Data Availability}

The data used to support the findings of this study are available from the corresponding author upon request.

\section{Conflicts of Interest}

The authors declare that there are no conflicts of interest regarding the publication of this paper.

\section{Acknowledgments}

This work was supported by the Key Scientific and Technological Project of Henan Province (192102310220); the Open Fund of Center for Levee Safety and Disease Prevention Engineering and Technology Research, Ministry of Water Resources (2019001), the Open Fund of Shaanxi Key Laboratory of Geotechnical and Underground Space Engineering (YT201906), and the Project of Outstanding Young Backbone Teachers of Xuchang University. The authors are sincerely grateful for their support.

\section{References}

[1] B. Shi, H. Jiang, Z. Liu, and H. Y. Fang, "Engineering geological characteristics of expansive soils in China," Engineering Geology, vol. 67, no. 1-2, pp. 63-71, 2002.

[2] A. R. Estabragh, B. Parsaei, and A. A. Javadi, "Laboratory investigation of the effect of cyclic wetting and drying on the behaviour of an expansive soil," Soils and Foundations, vol. 55, no. 2, pp. 304-314, 2015.

[3] Z. Huang, B. Wei, L. Zhang, W. Chen, and Z. Peng, "Surface crack development rules and shear strength of compacted expansive soil due to dry-wet cycles," Geotechnical and Geological Engineering, vol. 37, no. 4, pp. 2647-2657, 2019.

[4] S. Liu, Y. Lu, L. Weng, and F. Bai, "Field study of treatment for expansive soil/rock channel slope with soilbags," Geotextiles and Geomembranes, vol. 43, no. 4, pp. 283-292, 2015.

[5] L. Tang, S. Cong, L. Geng, X. Ling, and F. Gan, "The effect of freeze-thaw cycling on the mechanical properties of expansive soils," Cold Regions Science And Technology, vol. 145, pp. 197-207, 2018.

[6] L.-W. Kong, Z.-X. Zeng, W. Bai, and M. Wang, "Engineering geological properties of weathered swelling mudstones and their effects on the landslides occurrence in the Yanji section of the Jilin-Hunchun high-speed railway," Bulletin of Engineering Geology and the Environment, vol. 77, no. 4, pp. 1491-1503, 2018.

[7] L. U. Arenson, T. F. Azmatch, D. C. Sego et al., "A new hypothesis on ice lens formation in frost-susceptible soils," in Proceedings of the Ninth International Conference on Permafrost, vol. 1, pp. 59-64, Fairbanks, AK, USA, July 2008.

[8] H. R. Thomas, P. Cleall, Y.-C. Li, C. Harris, and M. KernLuetschg, "Modelling of cryogenic processes in permafrost and seasonally frozen soils," Géotechnique, vol. 59, no. 3, pp. 173-184, 2009.

[9] A. Steiner, P. J. Vardon, and W. Broere, "The influence of freeze-thaw cycles on the shear strength of illite clay," Proceedings of the Institution of Civil Engineers-Geotechnical Engineering, vol. 171, no. 1, pp. 16-27, 2017.

[10] H. Wu, Q. Ge, and J. B. Tian, "Study on the shear strength parameters under different freezing and thawing cycles of soil slope in China," Applied Mechanics and Materials, vol. 454, pp. 222-225, 2014.

[11] A. A. Korshunov, S. P. Doroshenko, and A. L. Nevzorov, "The impact of freezing-thawing process on slope stability of earth structure in cold climate," Procedia Engineering, vol. 143, pp. 682-688, 2016.

[12] M. Wang, S. Meng, Y. Sun, and H. Fu, "Shear strength of frozen clay under freezing-thawing cycles using triaxial tests," Earthquake Engineering and Engineering Vibration, vol. 17, no. 4, pp. 761-769, 2018.

[13] Y. Han, Q. Wang, N. Wang et al., "Effect of freeze-thaw cycles on shear strength of saline soil," Cold Regions Science and Technology, vol. 154, pp. 42-53, 2018.

[14] Z. Zhou, W. Ma, S. Zhang, Y. Mu, and G. Li, "Effect of freezethaw cycles in mechanical behaviors of frozen loess," Cold Regions Science and Technology, vol. 146, pp. 9-18, 2018.

[15] T. Liang, C. Shengyi, L. Xianzhang, W. Xing, and Z. Nie, “A unified formulation of stress-strain relations considering micro-damage for expansive soils exposed to freeze-thaw cycles," Cold Regions Science and Technology, vol. 153, pp. 164-171, 2018.

[16] J. Xu, Y. Li, W. Lan, and S. Wang, "Shear strength and damage mechanism of saline intact loess after freeze-thaw cycling," 
Cold Regions Science and Technology, vol. 164, Article ID 102779, 2019.

[17] Y. Lu, S. Liu, E. Alonso, L. Wang, L. Xu, and Z. Li, "Volume changes and mechanical degradation of a compacted expansive soil under freeze-thaw cycles," Cold Regions Science and Technology, vol. 157, pp. 206-214, 2019.

[18] Z. Lu, S. Xian, H. Yao, R. Fang, and J. She, "Influence of freezethaw cycles in the presence of a supplementary water supply on mechanical properties of compacted soil," Cold Regions Science and Technology, vol. 157, pp. 42-52, 2019.

[19] J. Liu, D. Chang, and Q. Yu, "Influence of freeze-thaw cycles on mechanical properties of a silty sand," Engineering Geology, vol. 210, pp. 23-32, 2016.

[20] J. Xu, W. Lan, Y. F. Li, S. Wang, W.-C. Cheng, and X. Yao, "Heat, water and solute transfer in saline loess under uniaxial freezing condition," Computers and Geotechnics, vol. 118, pp. 1-20, 2020.

[21] J. Xu, J. Ren, Z. Wang, S. Wang, and J. Yuan, "Strength behaviors and meso-structural characters of loess after freezethaw," Cold Regions Science and Technology, vol. 148, pp. 104-120, 2018.

[22] Y. L. Li and Z. L. Wang, "Shear strength degradation characteristics of expansive soil duringfreeze-thaw process considering moisture migration," Chinese Journal of Rock Mechanics and Engineering, vol. 38, pp. 1261-1269, 2019.

[23] Y. L. Li, J. Wang, and T. H. Wang, "Moisture migration of unsaturated soil due to thermal gradients," Rock and Soil Mechanics, vol. 37, pp. 2839-2844, 2016.

[24] S. Xian, Z. Lu, H. Yao, R. Fang, and J. She, "Comparative study on mechanical properties of compacted clay under freezethaw cycles with closed and open systems," Advances in Materials Science \& Engineering, vol. 2019, Article ID 9206372, 13 pages, 2019.

[25] X. Jie, H. Yang, J. Zhang, and X. Tang, "Properties of drained shear strength of expansive soil considering low stresses and its influencing factors," International Journal of Civil Engineering, vol. 16, no. 10, pp. 1389-1398, 2018.

[26] S. Akagawa, "Experimental study of frozen fringe characteristics," Cold Regions Science and Technology, vol. 15, no. 3, pp. 209-223, 1988.

[27] T. F. Azmatch, D. C. Sego, L. U. Arenson, and K. W. Biggar, "New ice lens initiation condition for frost heave in finegrained soils," Cold Regions Science and Technology, vol. 82, pp. 8-13, 2012.

[28] K. Watanabe and Y. Kugisaki, "Effect of macropores on soil freezing and thawing with infiltration," Hydrological Processes, vol. 31, no. 2, pp. 270-278, 2017.

[29] A. Hermansson and W. Spencer Guthrie, "Frost heave and water uptake rates in silty soil subject to variable water table height during freezing," Cold Regions Science and Technology, vol. 43, no. 3, pp. 128-139, 2005.

[30] Y. Zheng, W. Ma, and H. Bing, "Impact of freezing and thawing cycles on structure of soilsand its mechanism analysis by laboratory testing," Chinese Journal of Rock and Soil Mechanics, vol. 36, pp. 1282-1287, 2015.

[31] Y. Zhang, H. Bing, and C. S. Yang, "Influences of freeze-thaw cycles on mechanical properties of silty clay based on SEM and MIP test," Chinese Journal of Rock Mechanics and Engineering, vol. 34, pp. 3597-3603, 2015.

[32] X. Zhang and S. Sun, "The impact of soil freezing/thawing processes on water and energy balances," Advances in Atmospheric Sciences, vol. 28, no. 1, pp. 169-177, 2011.

[33] R. M. Nagare, R. A. Schincariol, W. L. Quinton, and M. Hayashi, "Effects of freezing on soil temperature, freezing front propagation and moisture redistribution in peat: laboratory investigations," Hydrology and Earth System Sciences, vol. 16, no. 2, pp. 501-515, 2012.

[34] X. Z. Xu, J. C. Wang, and L. X. Zhang, Frozen Soil Physics, Science Press, Beijing, China, 2010.

[35] F. Talamucci, "Freezing processes in porous media: formation of ice lenses, swelling of the soil," Mathematical and Computer Modelling, vol. 37, no. 5-6, pp. 595-602, 2003.

[36] H. Rahardjo, O. B. Heng, and L. E. Choon, "Shear strength of a compacted residual soil from consolidated drained and constant water content triaxial tests," Canadian Geotechnical Journal, vol. 41, no. 3, pp. 421-436, 2004.

[37] B. Zhang, Q. G. Zhao, R. Horn, and T. Baumgartl, "Shear strength of surface soil as affected by soil bulk density and soil water content," Soil and Tillage Research, vol. 59, no. 3-4, pp. 97-106, 2001.

[38] O. B. Andersland and B. Ladanyi, Frozen Ground engineering, John Wiley and Sons, Hoboken, NJ, USA, 2nd edition, 2004.

[39] J. Qi, P. A. Vermeer, and G. Cheng, "A review of the influence of freeze-thaw cycles on soil geotechnical properties," Permafrost and Periglacial Processes, vol. 17, no. 3, pp. 245-252, 2006.

[40] A. B. Hamilton, "Freezing shrinkage in compacted clays," Canadian Geotechnical Journal, vol. 3, no. 1, pp. 1-17, 1996.

[41] P. Viklander, "Permeability and volume changes in till due to cyclic freeze/thaw," Canadian Geotechnical Journal, vol. 35, no. 3, pp. 471-477, 1998.

[42] A. Kumar and D. K. Soni, "A review on freeze and thaw effects on geotechnical parameters," in International Conference on Sustainable Waste Management through Design, pp. 148-159, Springer, Berlin, Germany, 2018.

[43] P. A. G. Viran and A. Binal, "Effects of repeated freeze-thaw cycles on physico-mechanical properties of cohesive soils," Arabian Journal of Geosciences, vol. 11, no. 11, p. 250, 2018.

[44] E. Simonsen and U. Isacsson, "Soil behavior during freezing and thawing using variable and constant confining pressure triaxial tests," Canadian Geotechnical Journal, vol. 38, no. 4, pp. 863-875, 2001. 